\title{
Constitutive modeling of stress softening and permanent set in a porcine skin tissue: Impact of the storage preservation
}

\author{
A.S Caro-Bretelle ${ }^{\mathrm{a}, *, 1}$, P. Ienny ${ }^{\mathrm{a}}$, R. Leger ${ }^{\mathrm{a}}, \mathrm{S}$. Corn $^{\mathrm{a}}$, I. Bazin $^{\mathrm{c}}$, F. Bretelle $^{\mathrm{b}}$ \\ a C2MA, Ecole des Mines d'Alès, Alès, France \\ ${ }^{\mathrm{b}}$ Aix-Marseille Université, Unité de Recherche sur les Maladies Infectieuses Tropicales et Emergentes, UM63, CNRS 7278, IRD 198, INSERM 1095, Marseille, \\ France \\ c LGEI, Ecole des Mines d'Alès, Alès, France
}

\section{A B S T R A C T}

Prior to testing, soft tissues are usually maintained in different media and additives (solution, air, cryopreservant...) under various environment conditions (temperature, storage duration....). In many cases, results from mechanical tests performed on these stored tissues are supposed to be as closed as possible to the fresh ones. In the present work, cyclic tensile tests were performed with increasing values of strain on porcine skin tissues (excised following the Langer's lines) to enhance tissues mechanical nonlinearity such as softening behavior and permanent set. Optical methods were used to follow the inplane strains evolution. These latest values were used as data to simulate the structural behavior of these heterogeneous materials. The numerical simulation is based on the constitutive pseudo-elastic model accounting for the softening behavior as well as the permanent set. As a result, reliable material parameters were extracted from the experiments/model comparison for each storage solution. The result of this study reveals that preservation conditions must be carefully chosen: at low strain the tissues store in fridge in a saline solution during a short time, or in freezer $\left(-80^{\circ} \mathrm{C}\right)$ in water with cryopreservant and the fresh one lead to a similar mechanical response. For larger strain, the freezing $\left(-80^{\circ} \mathrm{C}\right)$ in water with cryopreservant is the only procedure for which the tissue recovers its initial behavior.

Keywords:

Porcine skin

Stress softening

Permanent set

Sample preservation

Digital Image Correlation

Pseudo-elasticity

\section{Introduction}

Biological soft tissues are mainly constituted with a collagen fibers network, elastin fibers and ground substance. The mechanical response under loading/unloading of such tissues is related to the complexity of its microstructure: during loading a first elastic response due to elastin is followed by the loading of collagen fibers (disentanglement, plastic deformation, rupture) and ground substance disruption or tearing (Usyk and Mcculloch, 2002); during unloading the mechanical response depends on the previously attained maximum load level phenomenon known as "Mullins effect" (Mullins, 1948) and a residual strain is maintained after complete unloading (Muñoz et al., 2008; Peña et al., 2011). Thus, constitutive mechanical modeling of these kinds of tissues must gather large deformations, anisotropic response, Mullins effect and permanent set. The anisotropic response of soft tissue is not the matter of this paper since the tested skin sample was always excised following the Langer's line and tested in

\footnotetext{
* Corresponding author. Tel.: 0033(0)466785631, fax: + 0033466785680.

E-mail address: Anne-Sophie.Caro@mines-ales.fr (A. Caro-Bretelle).

1 〈http://www.ema.fr $\rangle$.
}

the direction of this line. Isotropic hyperelastic response is currently introduced for rubber material via the definition of a strain energy (Mooney, 1940; Ogden, 1973). These stress/strain relationships can describe the nonlinear elastic isotropic behavior independently of the applied strain rate. Besides hyperelasticity, damage process arises during cyclic tensile tests (stress softening, permanent set). Concerning the modeling of the stress softening phenomenon, the Mullins effect, many different solutions have been used in the literature: the modification of the strain energy or the introduction of a criteria on the maximum principal elongation (Diani et al., 2009; Machado et al., 2010; Ogden and Roxburgh, 1999). Applied on soft material, some modelings have physical motivations (as damage of the collagenous components (Hurschler et al., 1997; Liao and Belkoff, 1999)) while others are more phenomenological (Horstemeyer and Bammann, 2010). Some models include both Mullins effects and permanent set (Ayoub et al., 2014; Dorfmann and Ogden, 2004), among them some are concerned with soft materials (Peña, 2014; Peña et al., 2011).

In this paper, we propose to use the Dorfmann and Ogden model to capture the non-linear behavior of porcine skin tissues. Tensile tests are instrumented with photomechanics to evaluate the in-plane strain field. The knowledge of all of its components 
(axial/transverse/shear) is a necessity to fully describe the mechanical behavior of these kinds of tissues. A set of modeling parameters (relative to hyperelasticity, stress softening and residual strain) is deduced from experiments to analyze the impact of preservation protocols on mechanical behavior. Prior to this modeling, an experimental research has been conducted by the authors on the same specimens (Caro-Bretelle et al., 2015). The impact of conservative procedures has been analyzed through the axial strain/stress curve shape.

\section{Materials and methods}

\subsection{Sample preparation and testing procedures}

Standard tensile tests on a universal testing Dartec machine (HC 10 Series, England) were instrumented with a high-resolution charge-coupled device (CCD) camera Redlake Megaplus II (E-Vision System Inc., Canada) (see Fig. 1a). Image acquisition $\left(1920 \times 1080\right.$ pixels, 256 grey levels) was performed by LabVIEW $^{\mathbb{R}}$ software (National Instruments, Nanterre, France), which allows the simultaneous acquisition of images (one image per second) and data provided by the testing machine (such as load and crosshead displacement). Skin samples were machined with a curved profile so that the neck initiation takes place within the observation field (Fig. 1b). A radius curvature of $10 \mathrm{~mm}$ is used to limit heterogeneities (stress heterogeneity remains inferior to 5\% (Christmann et al., 2011)). The sample preparation procedure has been fully described in a previous paper (Caro-Bretelle et al., 2015). Digital Image Correlation (DIC) (CinEMA ${ }^{\mathbb{R}}$ homemade software) was used to follow the in-plane strains (axial, transverse and shear) of a specific pattern displays as a square dotted line in Fig. $1 \mathrm{~b}$ (the principle of the methodology can be found in Christmann et al. (2011)).

Uniaxial cyclic tensile tests were performed according to the ISO 527 standard with a crosshead speed is equal to $1 \mathrm{~mm} / \mathrm{min}$ : they consist in a succession of loading/ unloading cycles with an increasing maximal force (10,20 and $50 \mathrm{daN}$ ) and a final load until fracture as described in (Fig. 1c). The viscoelastic effects are assumed to be negligible accounting the low imposed crosshead speed.

Let's define by $\vec{y}$ the tensile (axial) direction, $\vec{x}$ perpendicular to $\vec{y}$ in the planar surface (transverse direction) and $\vec{z}$ the out of plane direction.

The nominal stress components tensor are defined by the following expression:

$\boldsymbol{\sigma}=\sigma_{x x} \vec{x} \otimes \vec{x}+\sigma_{y y} \vec{y} \otimes \vec{y}=\sigma_{x x} \vec{x} \otimes \vec{x}+F / S_{0} \vec{y} \otimes \vec{y}$

where $F$ is the recorded load and $S_{0}=L_{0} h$ is the initial sample minimal cross section ( $L_{0}$ is the initial width at the minimal cross section and $h$ is the specimens thickness which is around $2 \pm 0.3 \mathrm{~mm}$ ). Taking into account the sample quotations and especially the low thickness in comparison with the others dimensions, the assumption of the plane stresses can be applied $\left(\sigma_{z z}=\mathbf{0}\right)$.

The deformation gradient tensor is defined by the following expression:

$\mathbf{F}=\lambda_{x x} \vec{x} \otimes \vec{x}+\lambda_{y y} \vec{y} \otimes \vec{y}+\lambda_{z z} \vec{z} \otimes \vec{z}$

where $\lambda_{x x}, \lambda_{y y}$ and $\lambda_{z z}$, the principal stretches ratios, are the eigenvalues of $\mathbf{F}$. The associated principal directions are $(\vec{x}, \vec{y}, \vec{z})$ since the investigated area (ZOI Fig. 1b) does not exhibit any shearing (Fig. 1c). The in-plane stretches are measured by DIC and correspond to the relative length variation of the pattern in the index direction. Assuming incompressibility (Maurel et al., 1998; Xu and Lu, 2011), the out-of-plane stretch ratio $\lambda_{z z}$ is deduced from the in-plane stretches ratio by the equation (see the plot result in Fig. 1):

$\operatorname{det}(\mathbf{F})=1$

The skins samples were extracted contiguously from the abdominal region of four pigs (with approximatively the same age and weight) following the spine direction (Fig. 2).

Skin specimens were preserved before testing following several procedures, as it is mentioned in Table 1. For each pig and each conservative procedure, three samples were tested to assess results reproducibility. Several conservation methods were chosen: the fridge during $2 \mathrm{~h}$ or the freezer during 7 days (at $-20^{\circ} \mathrm{C}$ or $-80^{\circ} \mathrm{C}$ ). The media as well differed from air to solution (saline with or without cryopreservant as glycerol/trehalose).

\subsection{Phenomenological modeling}

Typical nominal stress-strain curves are shown in Fig. 3. Porcine skin tissues behave as classical elastomer presenting a stress softening (with a significant reduction on the stress at a given level of strain, phenomenon known as the Mullins effect) and a permanent set (Dorfmann and Ogden, 2004; Mullins, 1948). Moreover the mechanical response to the unloading/loading cycle is partially hysteretic and should stabilize after the second cycle.

Since the non-linear response exhibited by the studied skin is highly nonlinear hyperelastic behavior should be considered as its elastic part. In particular, the constitutive behavior of such materials can be derived from the strain energy potentials with the assumption of isotropic material. The skin tissue is highly anisotropic; nevertheless in this study the samples are always excised in the same direction following the Langer lines and only the behavior in this axial direction has been considered and described here. $\tilde{W}:$

The Cauchy stress components can be expressed as function of a strain energy

$\sigma_{x x}=\lambda_{x x} \frac{\partial \tilde{W}\left(\lambda_{x x}, \lambda_{y y}\right)}{\partial \lambda_{x x}}, \sigma_{y y}=\lambda_{y y} \frac{\partial \tilde{W}\left(\lambda_{x x}, \lambda_{y y}\right)}{\partial \lambda_{y y}}$

In this study we choose the strain energy proposed by Ogden (1973) such that

$\tilde{W}\left(\lambda_{x x}, \lambda_{y y}\right)=\sum_{p=1}^{N} \mu_{p}\left(\lambda_{x x}^{\alpha_{p}}+\lambda_{y y}^{\alpha_{p}}+\lambda_{x x}^{-\alpha_{p}} \lambda_{y y}^{-\alpha_{p}}-3\right) / \alpha_{p}$

where $N$ is assumed to be 3 and $\mu_{p}, \alpha_{p}, p=1 . .3$ are real values.

Following the work of Ogden and Roxburgh (1999); Palmieri et al. (2009) an additional scalar damage variable $\left(\eta_{x}\right)$ is introduced through a damage function $\phi_{x}\left(\eta_{x}\right)$ to model the stress softening. During the loading process $\eta_{x}=1$ and $\phi_{x}(1)$ $=0$; during the unloading state $\eta_{x}$ is active.

The strain energy becomes in that case:

$W\left(\lambda_{x x}, \lambda_{y y}, \eta_{x}\right)=\eta_{x} \tilde{W}\left(\lambda_{x x}, \lambda_{y y}\right)+\phi_{x}\left(\eta_{x}\right)$

According to Ogden and Roxburgh (1999)

$\phi_{x}^{\prime}\left(\eta_{x}\right)=-\mu m \tan h^{-1}\left(r\left(\eta_{x}-1\right)\right)+W_{m}, \quad \mu=\frac{1}{2} \sum_{p=1}^{N} \mu_{p} \alpha_{p}$

where $W_{m}=\tilde{W}\left(\lambda_{m x x}, \lambda_{m y y}\right)$ and $\lambda_{m x x}, \lambda_{m y y}$ are the stretch values in the point on the primary load from which unload starts, being $\eta_{x}=1$ in this point; $r, m$ are positive dimensionless material constants.
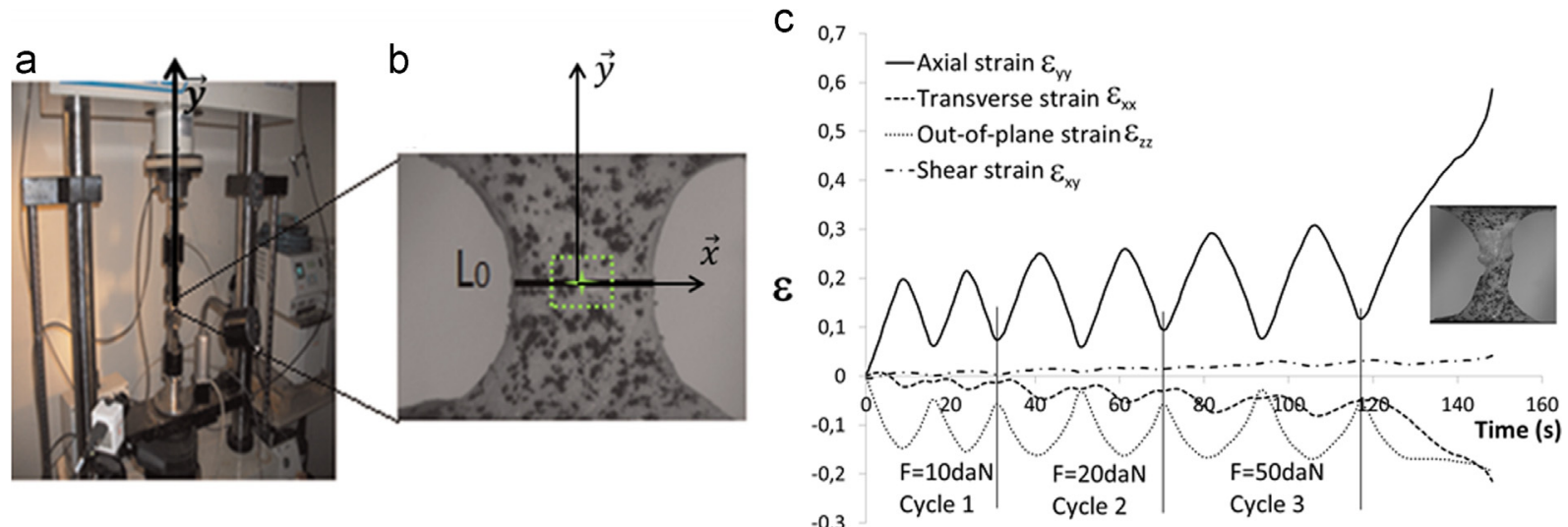

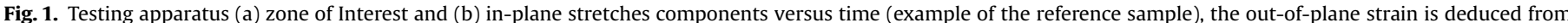
the incompressibility assumption (c). 


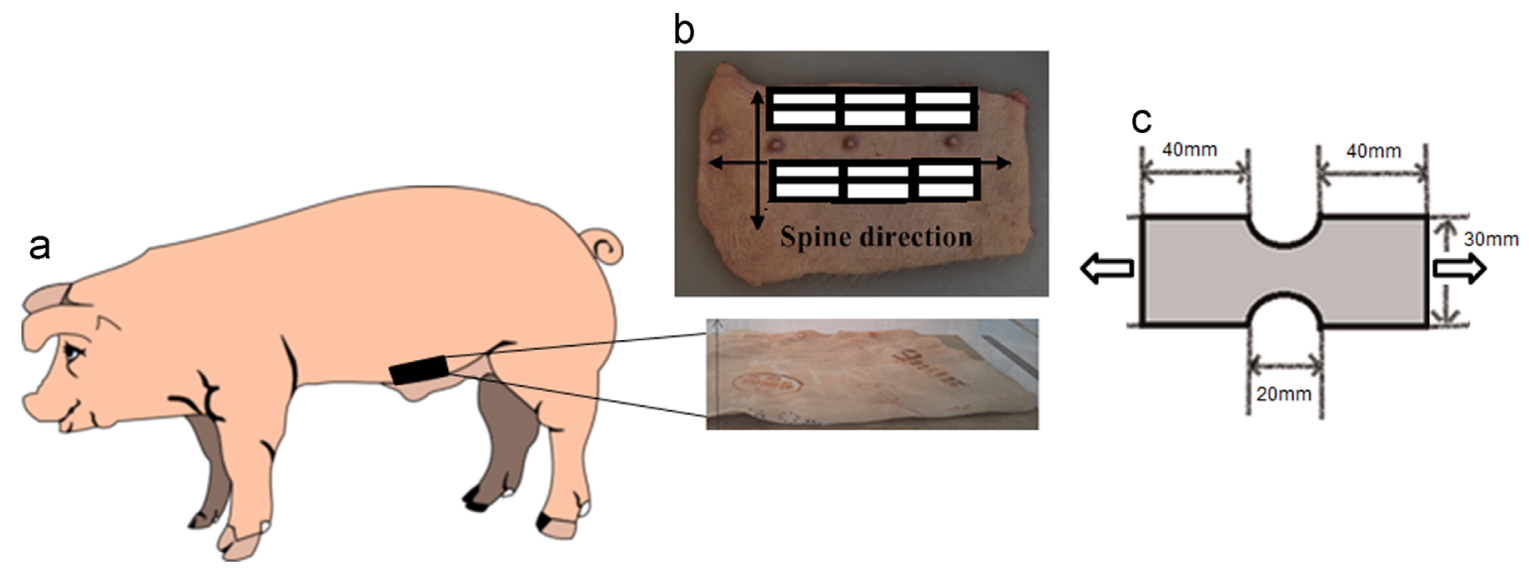

Fig. 2. Direction of native skin removal (a) native porcine skin before punching and (b) useful dimension of specimens (thickness 2 mm) (c).

Table 1

Conservation procedure.

\begin{tabular}{|c|c|c|c|c|c|}
\hline \multirow{2}{*}{$\begin{array}{l}\text { Tests } \\
4 \text { pigs }\left(c_{1}, c_{2}, c_{3}, c_{4}\right) 3 \text { samples by test }\end{array}$} & \multicolumn{5}{|c|}{ Conservation methods } \\
\hline & Temperature $\left({ }^{\circ} \mathrm{C}\right)$ & Storage duration & Mean & Media & Label \\
\hline \multirow{7}{*}{84 specimens } & +4 & $2 \mathrm{~h}$ & Fridge & Air & Ref \\
\hline & -20 & 7 days & Freezer & Air & $\mathrm{T}-20^{\circ} \mathrm{C}$ \\
\hline & -80 & 7 days & Freezer & Air & $\mathrm{T}-80^{\circ} \mathrm{C}$ \\
\hline & -80 & 7 days & Freezer & Saline solution + cryopreservant & $\mathrm{T}-80^{\circ} \mathrm{C}$ cryo \\
\hline & +4 & $4 \mathrm{~h}$ & Fridge & Saline solution & Salt $4 \mathrm{~h}$ \\
\hline & +4 & $24 \mathrm{~h}$ & Fridge & Saline solution & Salt $24 \mathrm{~h}$ \\
\hline & +4 & $72 \mathrm{~h}$ & Fridge & Saline solution & Salt $72 \mathrm{~h}$ \\
\hline
\end{tabular}

The expression of the damage variable is deduced from the Eqs. (6) and (7):

$\eta_{x}=1-\frac{1}{r} \tan h\left[\frac{W_{m}}{\mu m}\left(1-\frac{\tilde{W}\left(\lambda_{x x}, \lambda_{y y}\right)}{W_{m}}\right)\right]$.

The Cauchy stress components accounting stress softening can be expressed as function of this strain energy:

$\sigma_{x x}=\eta_{x} \lambda_{x x} \frac{\partial \tilde{W}\left(\lambda_{x x}, \lambda_{y y}\right)}{\partial \lambda_{x x}}, \sigma_{y y}=\eta_{x} \lambda_{y y} \frac{\partial \tilde{W}\left(\lambda_{x x}, \lambda_{y y}\right)}{\partial \lambda_{y y}}$.

Other variables are added to introduce the permanent set in the modeling Dorfmann and Ogden (2004): the residual strain variable $\eta_{y}$ and the associated function $\phi_{y}\left(\eta_{y}\right)$. During the loading process $\eta_{y}=1$ and $\phi_{y}(1)=0$; during the unloading state $\eta_{y}$ is active.

The energy function becomes:

$$
\begin{aligned}
W\left(\lambda_{x x}, \lambda_{y y}, \eta_{x}, \eta_{y}\right)= & \eta_{x} \tilde{W}\left(\lambda_{x x}, \lambda_{y y}\right)+\left(1-\eta_{y}\right) N\left(\lambda_{x x}, \lambda_{y y}\right) \\
& +\phi_{x}\left(\eta_{x}\right)+\phi_{y}\left(\eta_{y}\right)
\end{aligned}
$$

with

$N\left(\lambda_{x x}, \lambda_{y y}\right)=\frac{v}{2}\left[\lambda_{x x}^{2}+\lambda_{y y}^{2}+\lambda_{x x}^{-2} \lambda_{y y}^{-2}-3\right]$,

$v=\mu\left(U-V \tanh \left(\frac{\lambda_{m} y y-1}{Z}\right)\right)=-\phi_{y}^{\prime}\left(\eta_{y}\right)$

and

$\left.\eta_{y}=\tan h\left[\frac{\tilde{W}\left(\lambda_{x x}, \lambda_{y y}\right)}{W m}\right)^{\alpha}\right] / \tan h(1), \alpha=J+K \frac{W_{m}}{\mu}$

where $U, V, Z, J, K$ are five dimensionless dependent parameters.

Finally the stresses expressions are:

$\sigma_{x x}=\eta_{x} \lambda_{x x} \frac{\partial \tilde{W}\left(\lambda_{x x}, \lambda_{y y}\right)}{\partial \lambda_{x x}}+\left(1-\eta_{y}\right) \lambda_{x x} \frac{\partial N\left(\lambda_{x x}, \lambda_{y y}\right)}{\partial \lambda_{x x}}$,

$\sigma_{y y}=\eta_{x} \lambda_{y y} \frac{\partial \tilde{W}\left(\lambda_{x x}, \lambda_{y y}\right)}{\partial \lambda_{y y}}+\left(1-\eta_{y}\right) \lambda_{y y} \frac{\partial N\left(\lambda_{x x}, \lambda_{y y}\right)}{\partial \lambda_{y y}}$.

Assuming parameters $\gamma=\left(\alpha_{1}, \mu_{1}, \alpha_{2}, \mu_{2}, \alpha_{3}, \mu_{3}, r, m, J, K, U, V, Z\right.$ known, theoretical stresses/stretch curves were computed using the Matlab ${ }^{\mathbb{B}}$ software and the analytical model described in Eq. (12). These parameters can be adjusted to fit the

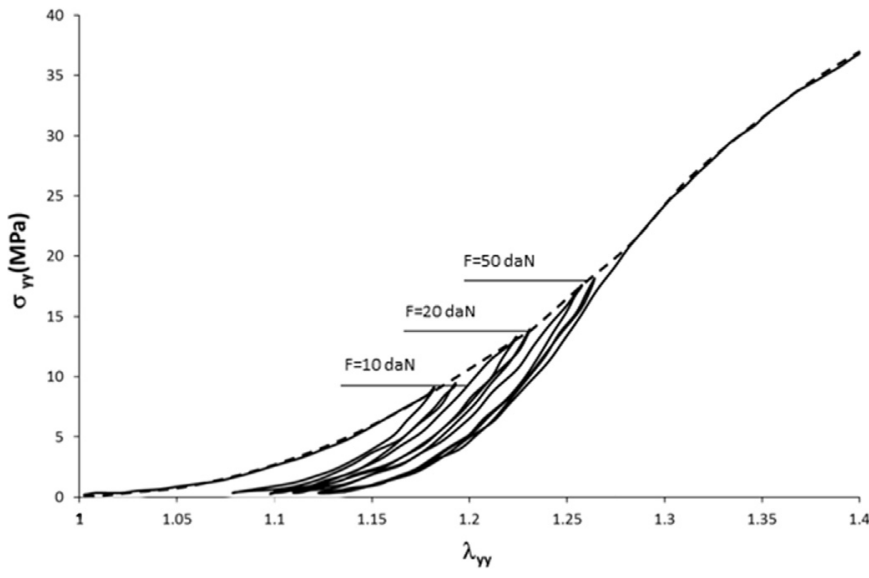

Fig. 3. Tension tests data: nominal stress versus axial stretch.

experimentally-determined nominal axial stress versus stretch curves. The least squares technique is employed to best fit the computed to the experimental stress.

Let $\sigma_{y y \text { exp }}$ be the vector of values of a nominal stress measured at each step of the test. The numerical model enables the computation of both axial and transverse stresses $\sigma_{x x}(\gamma), \sigma_{y y}(\gamma)$. At the minimum area, uniaxial tensile test should be considered, so the transverse stress is supposed to be close to zero. Because of the radius curvature at the minimum section, this latest assumption is not strictly respected: a non-homogeneous stress and strain is imposed within the sample. Nevertheless we suppose that in the central area, transverse stress is negligible with respect to the axial one. Indeed, taking into account the geometry of the test piece, and on the basis of an elastic behavior, the simulation of test shows that the transverse stress never exceeds $25 \%$ of the longitudinal one, and then modifies only by $6 \%$ the identified behavior. The gap between experimental and numerical values is computed via a cost function (CF) written as the squared 2-norm:

$C F(\gamma)=\frac{1}{2}\left(\sigma_{y y \exp }-\sigma_{y y}(\gamma)\right)^{t} \cdot\left(\sigma_{y y \exp }-\sigma_{y y}(\gamma)\right)+\frac{1}{2}\left(\sigma_{x x}(\gamma)\right)^{t} \cdot\left(\sigma_{x x}(\gamma)\right)$ 
Table 2

Hyperelastic material parameters fitted on the primary path loading.

\begin{tabular}{|c|c|c|c|c|c|c|c|}
\hline Conservation methods & $\boldsymbol{C F}\left(\gamma^{*}\right)$ & $\alpha_{1}\left(\mathbf{e}^{-01}\right)$ & $\alpha_{2}\left(\mathbf{e}^{-01}\right)$ & $\alpha_{3}\left(\mathbf{e}^{-01}\right)$ & $\mu_{1}(\mathrm{Mpa})\left(\mathrm{e}^{+02}\right)$ & $\mu_{2}(\mathrm{Mpa})\left(\mathrm{e}^{+02}\right)$ & $\mu_{3}(\mathrm{Mpa})\left(\mathrm{e}^{+02}\right)$ \\
\hline$+4^{\circ} \mathrm{C}$ during $2 \mathrm{~h}$ (Ref) & 1,0 & 27,0 & $-23,0$ & $-8,5$ & 1,0 & $-2,1$ & 8,9 \\
\hline$-20^{\circ} \mathrm{C}$ during 7 days & 1,2 & 12,9 & $-52,2$ & $-44,2$ & 1,4 & $-2,2$ & 2,9 \\
\hline$-80^{\circ} \mathrm{C}$ during 7 days & 0,9 & 4,7 & $-8,9$ & $-27,1$ & $-2,6$ & $-9,7$ & 2,7 \\
\hline$-80^{\circ} \mathrm{C}$ (cryopreserved) during 7 days & 1,4 & 20,1 & $-34,1$ & $-26,2$ & 6,5 & $-1,5$ & 2,5 \\
\hline Saline solution during $4 \mathrm{~h}$ & 0,6 & 25,2 & $-13,5$ & $-4,3$ & 2,2 & $-9,9$ & 40,4 \\
\hline Saline solution during $24 \mathrm{~h}$ & 0,5 & 7,9 & $-37,3$ & $-11,9$ & 6,6 & $-0,7$ & 6,4 \\
\hline Saline solution during $72 \mathrm{~h}$ & 0,7 & 41,8 & $-9,4$ & $-21,2$ & 0,0 & $-9,9$ & 4,4 \\
\hline
\end{tabular}

Table 3

Stress softening and permanent set material parameters fitted on the loading/unloading sequences.

\begin{tabular}{|c|c|c|c|c|c|c|c|}
\hline Conservation methods & $r\left(\mathbf{e}^{-01}\right)$ & $m\left(\mathbf{e}^{-01}\right)$ & $J$ & $K\left(\mathbf{e}^{-03}\right)$ & $U\left(\mathbf{e}^{-01}\right)$ & $V\left(\mathbf{e}^{-01}\right)$ & $Z\left(e^{-02}\right)$ \\
\hline$+4^{\circ} \mathrm{C}$ during $2 \mathrm{~h}$ (Ref) & 9,9 & 4,8 & 2,9 & 7,4 & 0,0 & 9,9 & 3,2 \\
\hline$-20^{\circ} \mathrm{C}$ during 7 days & 10,0 & 0,6 & 4,9 & 998,0 & 7,4 & 0,1 & 102,0 \\
\hline$-80^{\circ} \mathrm{C}$ during 7 days & 2,5 & 7,8 & 20,4 & 515,0 & 9,9 & 0,1 & 360,0 \\
\hline$-80^{\circ} \mathrm{C}$ (cryopreserved) during 7 days & 9,9 & 5,3 & 2,9 & 7,0 & 0,0 & 9,9 & 4,1 \\
\hline Saline solution during $4 \mathrm{~h}$ & 4,4 & 9,7 & 1,9 & 8,0 & 0,0 & 9,9 & 3,0 \\
\hline Saline solution during $24 \mathrm{~h}$ & 5,9 & 9,9 & 1,1 & 80,0 & 0,0 & 9,9 & 3,4 \\
\hline Saline solution during $72 \mathrm{~h}$ & 9,8 & 2,1 & 0,1 & 997,0 & 0,1 & 9,98 & 12,4 \\
\hline
\end{tabular}

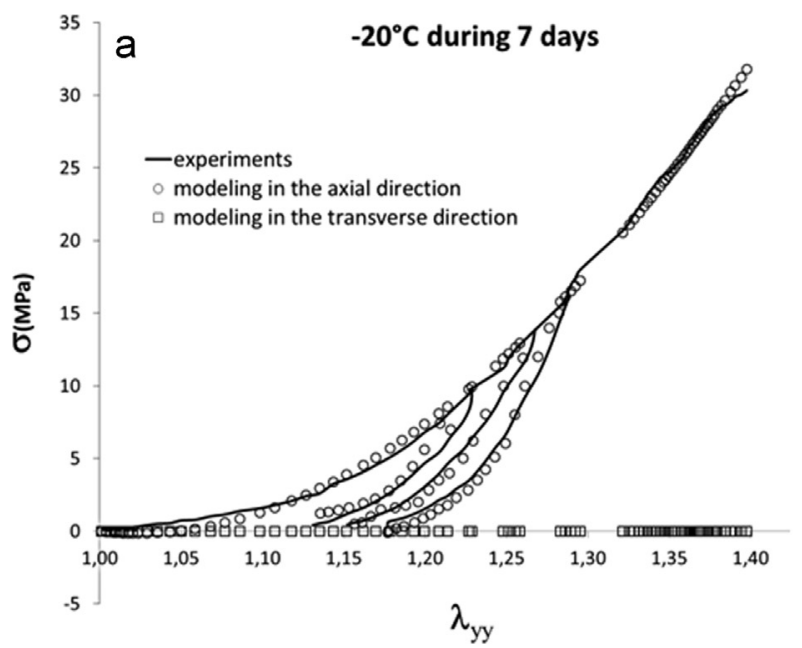

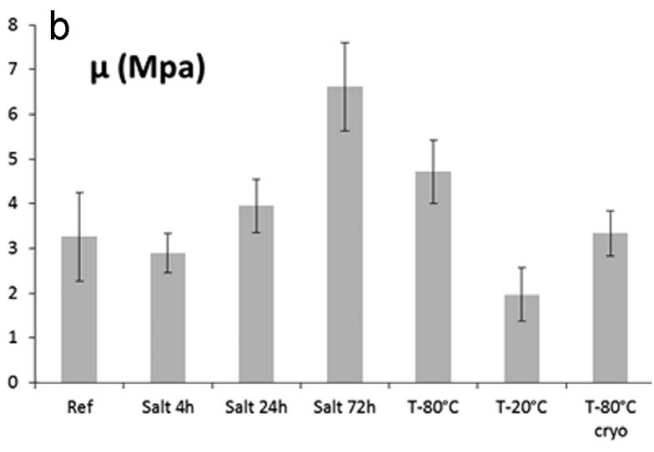

Average of 12 samples

Fig. 4. Tensile test: experimental and modeled stresses versus stretch (a) ground state shear modulus as a function of conservative procedure (b).

Hence, the minimization problem is given by

$$
C F\left(\gamma^{*}\right)=\min C F(\gamma)
$$

where $U$ is a set of constraints such that:

$U=\left\{\alpha_{1}, \mu_{1}, \alpha_{2}, \mu_{2}, \alpha_{3}, \mu_{3}, r, m, J, K, U, V, Z \in \mathbb{R}^{13} ;\right.$

$\left.\alpha 1 \mu_{1}+\alpha_{2} \mu_{2}+\alpha_{3} \mu_{3} \geq 0 ; r \geq 0 ; m \geq 0\right\}$

The numerical optimization algorithm is Constrained Levenberg-Marquardt (Marquardt, 1963) which is rather classical in the literature for solving identification problem.

\section{Results}

After approximatively 10 iterations for all the tested samples, the minimization problem defined by (15) converged toward optimized parameters $\gamma^{*}$. This convergence was ensured whatever the starting value was taken within $U$, set of constrained admissible parameters. The results of the identification process are listed in Tables 2 and 3 with the value of the associated cost function $C F\left(\gamma^{*}\right)$ defined in (14). The first table is concerned by the hyperelastic part of the behavior. The primary path loading is used to fit six of the parameters $\left(\alpha_{1}, \mu_{1}, \alpha_{2}, \mu_{2}, \alpha_{3}, \mu_{3}\right)$. The second table gathers the irreversible material parameters: $(r, m, J, K, U, V, Z)$ on the bases of the last unloading data (for each of the three cycles). The identified parameters are significantly affected by the conservative protocol with a $p$-Value $(p)$ which always remains lower than 0.0001 . The identification also indicated significant correlations $(p \leq 0.03)$ for all experimental tests reproduced on samples with the same history. The experimental and numerical stressesstretch in the central area of the specimen are shown in Fig. 4a for a sample preserved in a freezer $\left(-20^{\circ} \mathrm{C}\right)$ during 7 days. Optimized parameters allowed the model to match the expected experimental data in all the range of deformations, with a transverse stress close to zero. The value of the cost function never exceed 1,4. For sake of clarity standard deviation are introduced directly in the plotted graphs. In order to assess this identification procedure, the sensitivity of the cost function with respect to the parameters. A sensitivity parameter is computed:

$S\left(\gamma^{*}\right)=\left|\frac{\left[\left(C F\left(\gamma^{*}+\Delta \gamma^{*}\right)-C F\left(\gamma^{*}\right)\right)\right] / C F\left(\gamma^{*}\right)}{\Delta \gamma^{*} / \gamma^{*}}\right|, \Delta \gamma^{*}=5 \%$ 
Table 4

Sensitivity analysis of the material set parameters on the cost function (example of the reference sample).

\begin{tabular}{|c|c|c|c|c|c|c|c|c|c|c|c|c|}
\hline$\alpha_{1}$ & $\alpha_{2}$ & $\alpha_{3}$ & $\boldsymbol{\mu}_{1}$ & $\boldsymbol{\mu}_{2}$ & $\boldsymbol{\mu}_{3}$ & $r$ & $m$ & $J$ & $K$ & $\boldsymbol{U}$ & $V$ & $Z$ \\
\hline 2.3 & 0.14 & 0.76 & 2.5 & 0.46 & 0.5 & 0.2 & 0.08 & 0.005 & 0.35 & 0.05 & 0.16 & 0.04 \\
\hline
\end{tabular}

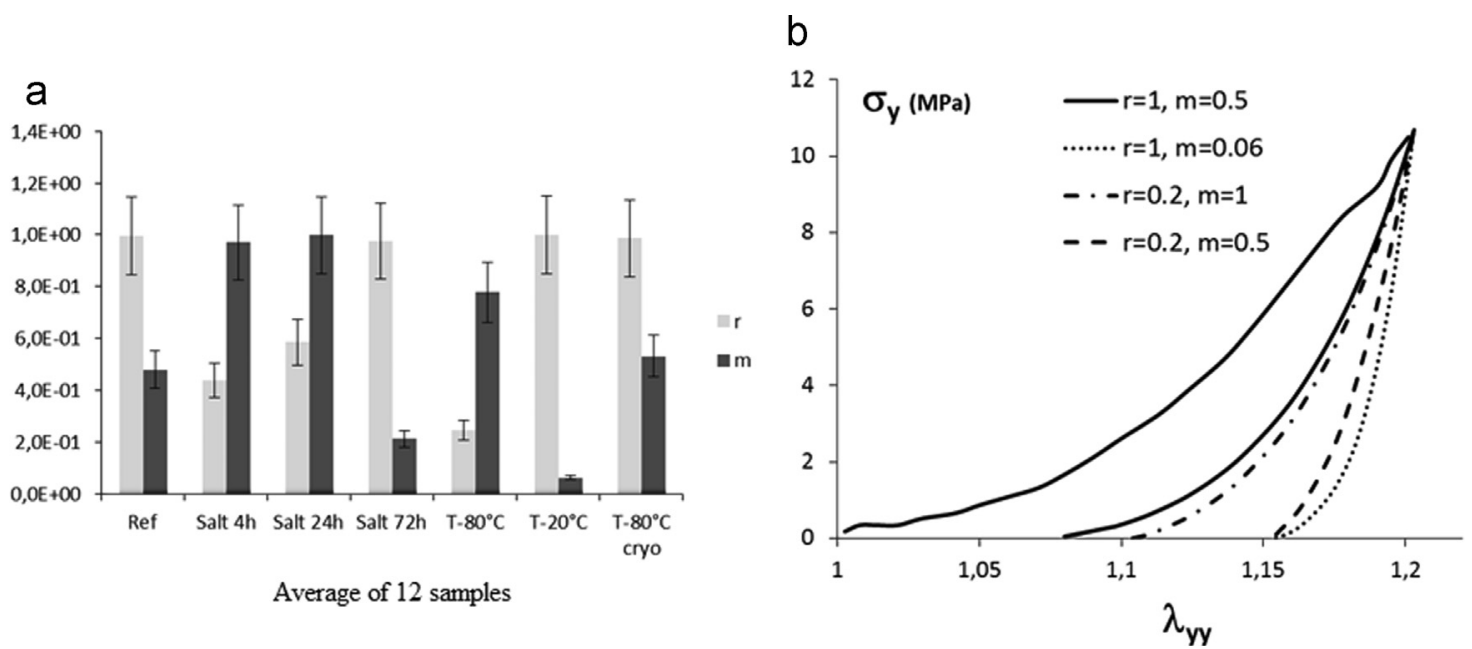

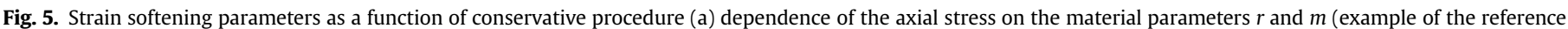
sample, plotted in continuous line) (b).

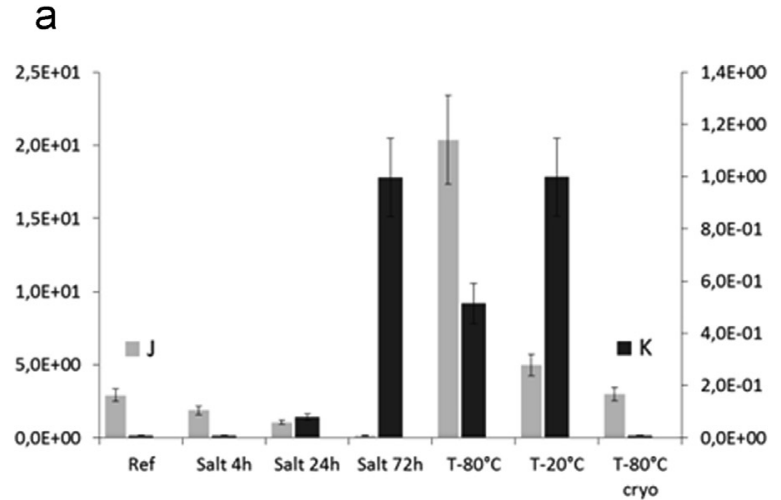

Average of 12 samples b

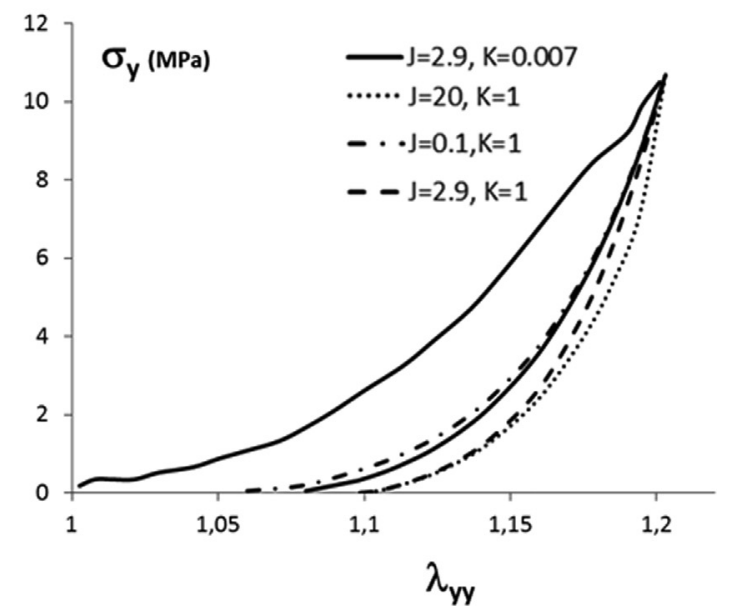

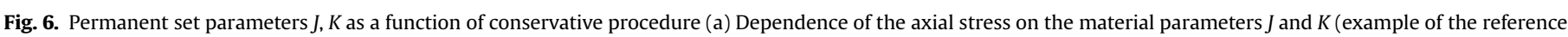
sample, plotted in continuous line) (b).

Table 4 shows the evaluation of sensitivity for each material parameter, for the reference sample. The lower is this parameter, the better sensitive is the method with respect to the parameter.

\section{Discussion}

These results bring to light that the conservative procedure impacts the mechanical behavior: the nonlinearity as well as the irreversible behavior. The sensitivity analysis (Table 4) reveals that cost function is sensitive to a parameter variation, especially for the parameter describing the Mullins effect and the permanent set (sensitivity parameter never exceeding 0.2 ). Therefore, parameters are well fitted by minimizing the chosen cost function. The ground state shear modulus which is a combination of all the hyperelastic contributions $\left(\mu=\alpha_{1} \mu_{1}+\alpha_{2} \mu_{2}+\alpha_{3} \mu_{3}\right)$ is plotted in Fig. $4 \mathrm{~b}$. The saline solution (after $4 \mathrm{~h}$ of conservation) alters the hyperelastic behavior at low strain by progressively increasing the material shear modulus. The freezing methods appear to drastically modify the shear modulus; however the addition of cryopreservant seems to be a necessity to maintain identically to the reference state these initial properties. These conclusions are in accordance with those of the previous analysis (Caro-Bretelle et al., 2015): the raw data extracted from the stress/strain curve lead to an elastic modulus maintained for a storage at $-80{ }^{\circ} \mathrm{C}$ with cryopreservant. Nevertheless, the freezing at $-20^{\circ} \mathrm{C}$ decreases the initial shear modulus, despite the results presented in the companion paper. 

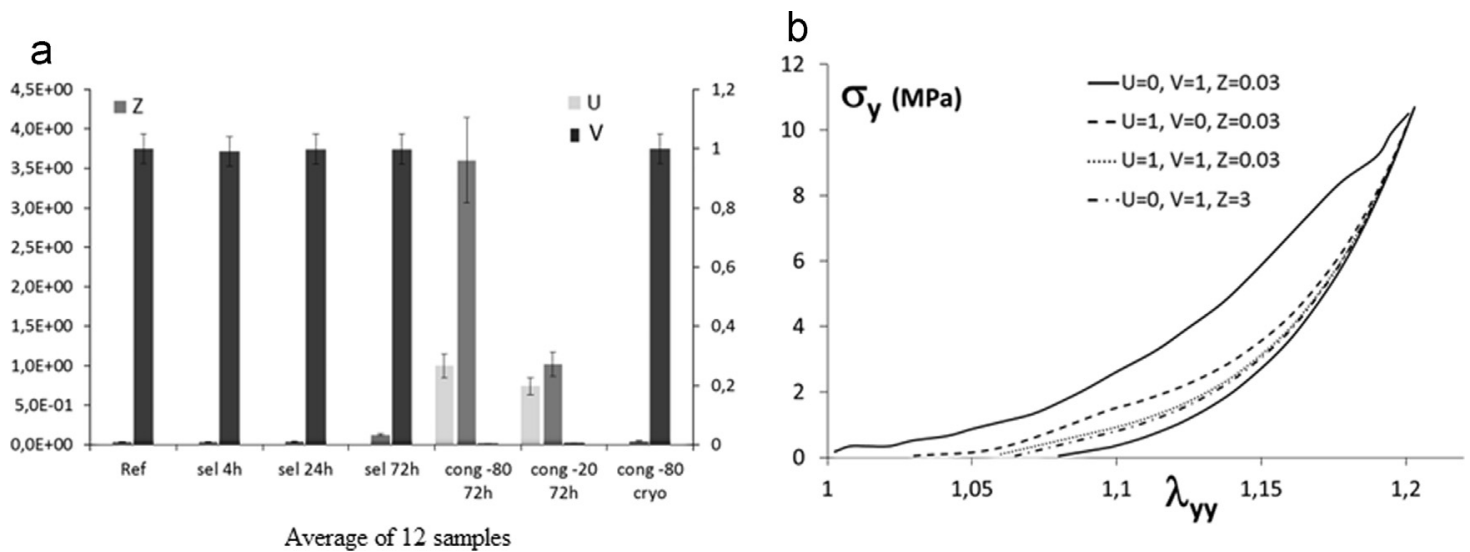

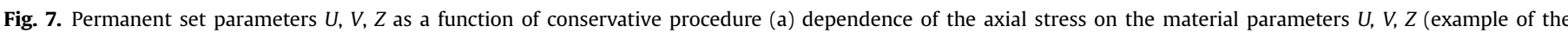
reference sample, plotted in continuous line) (b).

Concerning the stress softening, the evolution of $r$ and $m$ are plotted in a histogram as a function of conservation procedure in Fig. 5a. The plot of the sensitivity with respect to $r$ and $m$ of axial stress is shown in Fig. 5b: the lower is the value of $r$, the higher is the stress softening (Mullins effect); the $m$ parameter reflects the curvature of the stress reduction independently of $r$. Saline preservation and freezing without cryopreservant increases the Mullins effect. Once again the freezing at $-80{ }^{\circ} \mathrm{C}$ with cryopreservant maintains the level of strain softening relative to the reference one. The experimental part of this work Caro-Bretelle (2015) does not study directly Mullins effect, but its consequences via the evolution of damage parameters which describe the beginning of the stress softening. The main conclusion was that immersion in saline solution during a short time (prior to $24 \mathrm{~h}$ ) maintains these damage parameters (in comparison with the reference sample). This may be the case, but integrating all the raw data during the unloading path, the conclusion via the modeling approach of the Mullins effect is not the same. The only way to maintain the Mullins effect is the freezing at $-80^{\circ} \mathrm{C}$ with cryopreservant.

Concerning the permanent set, the values of material parameters $(J, K, U, V, Z)$ are displayed in Figs. $6 a$ and $7 \mathrm{a}$. The plot of the sensitivity with respect to $(J, K, U, V, Z)$ of axial stress is shown in Figs. $6 \mathrm{~b}$ and $7 \mathrm{~b}$. The immersion in saline solution decreases the value of $J$ and increase the one of $K$ thus impacting the plasticity parameter. An opposite trend is observed in the case of freezing excepted when cryopreservant is added: both $J$ and $K$ increased, increasing thus the permanent set value. Concerning the last 3 parameters $(U, V, Z)$, all the conservative procedures lead to a decrease of the plastic parameter. Once again it's difficult to compare this results to the one obtained in the companion paper. Here the permanent set is described through all the unloading process whereas in Caro-Bretelle et al. (2015) only the value after complete unloading is recorded.

\section{Conclusion}

The main goal of this paper was first to use a robust constitutive modeling to describe hyperelasticity, Mullins effects and permanent set, three phenomenon currently observed in soft tissues subjected to cyclic tensile loadings and secondly to relate parameters of this modeling to sample storage conditions (physical and/or chemical). The analysis relies on the knowledge of the in-plane strains data (axial/transverse/shear) to describe the structural mechanical test; these data are fundamental to a reliable parameters identification and thus to a samples mechanical comparison.

The material under study is porcine skin and tensile tests performed on samples always excised in the Langer's direction are associated with a non-contact measurement of strain. The chosen pseudoelastic model enables an accurate reproduction of the numerical stress accounting the transverse and axial stretches. This was not the case in the experimental part of this research Caro-Bretelle et al. (2015). After parameters identification it was found that at low strain the tissues stored in fridge in a saline solution during a short time, or in freezer $\left(-80^{\circ} \mathrm{C}\right)$ in water with cryopreservant and the fresh one lead to a similar mechanical response. For larger strain the freezing $\left(-80^{\circ} \mathrm{C}\right)$ in water with cryopreservant is the only procedure for which the tissue recovers its initial behavior.

A perspective of this work is to associate mechanical and microstructural characterisation via the analysis of damaged tissue. The effects of cryopreservation on collagen integrity by histological analyses and collagen levels analyses have to be performed. The use of others cryoprotectants like EG (ethylene glycol) or DMSO (Dimethyl sulfoxide) for cryopreservation can be performed too.

\section{Conflict of interest statement}

None declared.

\section{References}

Ayoub, G., Zaïri, F., Naït-Abdelaziz, M., Gloaguen, J.M., Kridli, G., 2014. A viscohyperelastic damage model for cyclic stress-softening, hysteresis and permanent set in rubber using the network alteration theory. Int. J. Plast. 54, 19-33. http://dx.doi.org/10.1016/j.ijplas.2013.08.001.

Caro-Bretelle, A.S., Gountsop, P.N., Ienny, P., Leger, R., Corn, S., Bazin, I., Bretelle, F. 2015. Effect of sample preservation on stress softening and permanent set of porcine skin. J. Mech. Behav. Biomed. Mater. J. Biomech. http://dxdoi.org/ 10.1016/j.jbiomech.2015.07.014

Christmann, A, Ienny, P, Quantin, J.C. Caro-Bretelle, A.S, Lopez-Cuesta, JM. 2011. Mechanical behaviour at large strain of polycarbonate nanocomposites during uniaxial tensile test. Polym. (Guildf). http://dxdoi.org/10.1016/j.polymer.2011.06.056

Diani, J., Fayolle, B., Gilormini, P., 2009. A review on the Mullins effect. Eur. Polym. J. 45, 601-612. http://dx.doi.org/10.1016/j.eurpolymj.2008.11.017.

Dorfmann, A., Ogden, R.W., 2004. A constitutive model for the Mullins effect with permanent set in particle-reinforced rubber. Int. J. Solids Struct. 41, 1855-1878. http://dx.doi.org/10.1016/j.ijsolstr.2003.11.014.

Horstemeyer, M.F., Bammann, D.J., 2010. Historical review of internal state variable theory for inelasticity. Int. J. Plast. 26, 1310-1334. http://dx.doi.org/10.1016/j. ijplas.2010.06.005.

Hurschler, C., Loitz-Ramage, B., Vanderby, R., 1997. A structurally based stressstretch relationship for tendon and ligament. J. Biomech. Eng. 119, 392-399. http://dx.doi.org/10.1115/1.2798284.

Liao, H., Belkoff, S.M., 1999. A failure model for ligaments. J. Biomech. 32, 183-188. http://dx.doi.org/10.1016/S0021-9290(98)00169-9. 
Machado, G., Chagnon, G., Favier, D., 2010. Analysis of the isotropic models of the Mullins effect based on filled silicone rubber experimental results. Mech. Mater. 42, 841-851. http://dx.doi.org/10.1016/j.mechmat.2010.07.001.

Marquardt, D.W., 1963. An algorithm for least-squares estimation of nonlinear parameters. J. Soc. Ind. Appl. Math. http://dx.doi.org/10.1137/0111030.

Maurel, W., Thalmann, D., Wu, Y., Thalmann, N., Magneat Thalman, N., Thalman, D. 1998. Biomechanical Models for Soft Tissue Simulation. Springer. http://dx.doi org/10.1007/978-3-662-03589-4.

Mooney, M., 1940. A theory of large elastic deformation. J. Appl. Phys. 11, 582-592. http://dx.doi.org/10.1063/1.1712836.

Mullins, L., 1948. Effect of stretching on the properties of rubber. Rubber Chem Technol. http://dx.doi.org/10.5254/1.3546914.

Muñoz, M.J., Bea, J.A., Rodríguez, J.F., Ochoa, I., Grasa, J., Pérez del Palomar, A. Zaragoza, P., Osta, R., Doblaré, M., 2008. An experimental study of the mouse skin behaviour: damage and inelastic aspects. J. Biomech. 41, 93-99. http://dx. doi.org/10.1016/j.jbiomech.2007.07.013.

Ogden, R.W., 1973. Large deformation isotropic elasticity-On the correlation of theory and experiment for incompressible rubberlike solids. Rubber Chem. Technol. http://dxdoi.org/10.5254/1.3542910
Ogden, R.W., Roxburgh, D.G., 1999. A pseudo-elastic model for the Mullins effect in filled rubber. Proc. R. Soc. A Math. Phys. Eng. Sci.http://dxdoi.org/10.1098/ rspa.1999.0431

Palmieri, G., Sasso, M., Chiappini, G., Amodio, D., 2009. Mullins effect characterization of elastomers by multi-axial cyclic tests and optical experimental methods. Mech. Mater. 41, 1059-1067. http://dx.doi.org/10.1016/j.mechmat.2009.05.002.

Peña, E., 2014. Computational aspects of the numerical modelling of softening, damage and permanent set in soft biological tissues. Comput. Struct. 130, 57-72. http://dx.doi.org/10.1016/i.compstruc.2013.10.002.

Peña, E., Martins, P., Mascarenhas, T., Natal Jorge, R.M., Ferreira, A., Doblaré, M., Calvo, B., 2011. Mechanical characterization of the softening behavior of human vaginal tissue. J. Mech. Behav. Biomed. Mater. 4, 275-283. http://dx.doi.org/ 10.1016/j.jmbbm.2010.10.006.

Usyk, T.P., Mcculloch, A.D., 2002. Computational methods for soft tissue biomechanics. Biomech. Soft Tissue Cardiovasc. Syst. 441, 273-342. http://dx.doi. org/10.1007/978-3-7091-2736-0 7.

$\mathrm{Xu}, \mathrm{F} ., \mathrm{Lu}, \mathrm{T} ., 2$ 2011. Introduction of Skin Biothermomechanics. In: Introduction to skin biothermomechanics and thermal pain. Springer, pp. 209-220. 